\title{
Cognitive behavioural therapy reduced distress and doctor visits in patients with medically unexplained symptoms
}

Sumathipala A, Hewege S, Hanwella R, et al. Randomized controlled trial of cognitive behaviour therapy for repeated
consultations for medically unexplained complaints: a feasibility study in Sri Lanka. Psychol Med 2000 Jul;30:747-57.

QUESTION: In patients with medically unexplained symptoms and repeated clinic visits, is cognitive behavioural therapy (CBT) more effective than standard care in reducing symptoms, visits, and distress?

Design

3 month randomised (allocation concealed*), blinded (2 outcome assessors)*, controlled trial.

\section{Setting}

A primary care clinic in a hospital in Colombo, Sri Lanka.

\section{Patients}

68 patients who were $16-65$ years of age (mean age $38 \mathrm{y}$, $71 \%$ women) and had presented repeatedly at the primary care clinic in the previous 6 months (mean 14 visits/y) with $\geqslant 5$ medically unexplainable symptoms (distinctive subjective sensation or personal observation in relation to the body which the patient described as abnormal). Exclusion criteria were the presence of such organic psychiatric disorders as dementia, alcohol dependence, psychosis, or active suicidal thoughts; or current receipt of psychiatric treatment. Follow up was $66 \%$ at 3 months; all patients were included in the intention to treat analysis.

\section{Intervention}

Patients were allocated to six 30 minute sessions over 3 months of CBT $(n=34)$ or to standard care $(n=34)$. CBT involved structured regular visits to 1 psychiatrist. Patients were made aware of the psychological component of their condition and helped to reduce unnecessary consultations. Attempts were made to include a patient's carer, usually their spouse, to prevent discussions with ill informed friends or relatives. Patients were encouraged to keep diaries to express distress and monitor symptoms, and urged to take control over their dysfunctional thinking and behaviour. Patients in the standard care group consulted their usual healthcare providers and could visit doctors of their choice.

\section{Main outcome measures}

Symptoms, patient initiated visits, level of distress or psychiatric morbidity (General Health Questionnaire [GHQ]-30), symptom score (Bradford Somatic Inventory [BSI] and 2 open ended questions), and patients' perceived satisfaction.

\section{Main results}

Analysis was by intention to treat using the last observation carried forward method. At 3 months, patients in the CBT group had fewer symptoms $(\mathrm{p}=0.001)$, fewer visits $(\mathrm{p}=0.004)$, a lower GHQ score $(\mathrm{p}=0.04)$, and a lower BSI score $(\mathrm{p}=0.01)$ than patients in the standard care group (table). A sensitivity analysis in which worst outcomes were substituted for missing values did not alter the results. $61 \%$ of patients in the CBT group were satisfied with treatment compared with $15 \%$ in the standard care group $(\mathrm{p}=0.05)$.

\section{Conclusion}

In patients with medically unexplained symptoms and repeated clinic visits, cognitive behavioural therapy reduced symptoms, distress, and patient initiated visits. *See glossary.
Source of funding: Wellcome Trust, UK

For correspondence: Dr A Sumathipala, Section of Epidemiology and General Practice, Institute of Psychiatry, King's College London, De Crespigny Park, London SE5 8AF, UK. spjuats@iop.kcl.ac.uk.

Cognitive behavioural therapy (CBT) v standard care for medically unexplained symptoms at 3 months, adjusted for baseline score

\begin{tabular}{lrcl} 
Outcomes & CBT & $\begin{array}{l}\text { Standard } \\
\text { care }\end{array}$ & $\begin{array}{l}\text { Difference in } \\
\text { means (95\% CI) }\end{array}$ \\
Symptoms (mean number) & 3.8 & 6.1 & $2.3(0.8$ to 3.7) \\
\hline Patient initiated visits (mean number) & 3.1 & 7.9 & $4.8(1.3$ to 8.0$)$ \\
\hline General Health Questionnaire score & 6.3 & 10.4 & $4.1(0.5$ to 7.6$)$ \\
\hline Bradford Somatic Inventory score & 13.2 & 15.6 & $2.3(0.5$ to 5.2$)$ \\
\hline
\end{tabular}

\section{COMMENTARY}

Patients with unexplained physical complaints are often considered difficult to manage by primary care physicians. At the same time these patients have a high rate of heathcare use and show considerable functional impairment. ${ }^{1}$ Sumathipala $e t$ al's trial of CBT for patients who repeatedly present with such complaints is a first step in evaluating 1 approach to treating these patients. The results support the effectiveness of the CBT approach in reducing use and degree of patient distress, and in increasing patient satisfaction with care. But no data exist about the stability of the improvements or about treatment discontinuation effects.

Some limitations exist as to what primary care and other clinicians can apply from the results to their own practices. Firstly, the problem of dropouts (34\%) from both the recruitment and intervention stages is considerable given the importance of engaging patients in an alternative, non-medical approach to reducing their distress. Secondly, no data are presented about which of the CBT components are active in promoting the noted improvements. Simply providing regular appointments (6 in $3 \mathrm{mo}$ ) and focusing on functional rather than physical problems may have been enough to reduce patient initiated visits and complaints about symptoms for some patients. Good reasons exist to suggest that these techniques be recommended as standard management. Finally, as many as $50 \%$ of patients presenting with unexplained physical problems have psychiatric disorders, in particular major depressive disorder, generalised anxiety disorder (GAD), or panic disorder. ${ }^{2}$ It would have been useful to know if a relation existed among psychiatric disorders, retention, and post-treatment outcome. Such data would assist clinicians in making decisions about which patients to manage with standard care, which to treat with a generic approach such as the one Sumathipala et al use, and which to treat more specifically with CBT techniques that have been empirically validated for the treatment of depression, $\mathrm{GAD}$, and panic disorder.

Richard O'Kearney, BA, Dip App Psych, MPsych University of New South Wales Sydney, Australia

1 Katon WJ, Walker EA. Medically unexplained symptoms in primary care.J Clin Psychiatry 1998;59(suppl 20):15-21.

2 Simon GE, Von Korff M. Somatization and psychiatric disorder in the NIMH epidemiologic catchment area study. Am J Psychiatry 1991;148:1494-500. 